\title{
Structural geology modelling: a summary on data integrity and modelling methods
}

\author{
K.M. Rees Golder Associates Pty Ltd, Australia \\ J. Graaf Golder Associates Pty Ltd, Australia
}

\begin{abstract}
The creation of a structural geology model greatly improves the geotechnical understanding of a deposit by giving meaning to the thousands of defect measurements collected. Structural geology models are all about geometry; geometry of the various rock packages and geometry of the overriding structural framework. Geotechnical models on the other hand deal in the details; the statistical defect set orientations, the spacing between the defects and their infill and surface characteristics. In order to get an overall picture of the rock mass, the geotechnical model needs to be assessed in association with the structural geology model and vice versa. Structural geology models incorporate a vast array of data types, including drillhole, televiewer, conventional geological mapping, photogrammetric geological mapping, etc., but how accurate and complete is all of this data? The integration of multiple data types into a structural geology model can be fraught with complications. Varying levels of accuracy occur between different datasets and these variants need to be assessed prior to structural geology modelling. Where conflict exists between multiple data types, the most accurate data should be used, thus it is important to understand data accuracy. Drillhole data for example can be affected by inaccurate orientation marks and survey pickups, leading to inaccurate structural measurements. Furthermore, the spacing and orientation of drillholes often does not provide a representative sample of the rock mass as the drill design is generally tailored to the geometry of the ore body for resource modelling. These factors need to be understood when using the data to create a structural geology model. While orientated drillhole data provides a good basis, integrating other data types such as geological mapping provides for a more robust model, however conventional geological modelling comes with its own set of issues.

Advances in data collection techniques can enable many of the issues associated with poor data quality to be overcome. Televiewer data can be used to validate drill core logging data, while photogrammetry techniques can enable accurate digital geological maps to be created. However, regardless of the method employed, it is paramount that adequately trained personal carry out the mapping to ensure high quality data. The purpose of this paper is to discuss the quality of data used in structural geology modelling and present reasons for applying new technologies to your mining operation or resource assessment.
\end{abstract}

\section{Introduction}

Structural geology models portray a wealth of information ranging from regional scale structures down to intermediate scale jointing. These play a significant role in the integrity and characteristics of the rock mass. The ability to portray this information often comes down to the type of data used and the level of detail collected. Whilst geological mapping and drillhole logging account for the majority of the data used for structural geology modelling, the quality and accuracy of these data can vary greatly depending upon the collection method and the person collecting the information. In addition, geophysical surveys such as magnetics improve the understanding of the geological environment which can be useful when designing geotechnical drill programs with little geological information.

Conventional geological mapping can be carried out at various levels. Depending upon the experience and expertise of the geologist, engineering geologist or geotechnical engineer collecting these data, vastly different levels of detail is often collected, which can result in missed information. This missed information can have a significant impact on future interpretations. Ideally all information would be collected; however 
this is not necessarily practical given time constraints and the level of experience of the person collecting the data.

Alternatively, photogrammetry can be undertaken in addition to conventional mapping, preserving the raw data for future analysis. As photogrammetry provides a scaled and orientated 3D photograph of the area, a detailed analysis by experienced personnel can take place as and when required, and is particularly valuable following rock falls or slope instabilities. Conventional mapping is limited in regard to this as access is often limited due to safety concerns. Photogrammetry enables assessment of the entire slope to be undertaken; however limitations still exist with this method. Small scale geotechnical parameters such as roughness and infill cannot be recorded using photogrammetry. One method for alleviating this issue is to correlate joint set characteristics with either drillhole data or field observations.

Drillhole data can come in a variety of forms including reverse circulation (RC) chips, diamond drill core and borehole imagery (i.e. televiewer and formation microimager (FMI) logs) and provides variable levels of information. It is important to understand the type of data being used and its limitations. General trends in the lithological geometry can be obtained from RC drilling; however for a more detailed understanding of the rock mass, the use of either diamond core or borehole image data is essential. The most useful information from drilling comes from orientated drill core, although this cannot always be trusted. Errors in orientation mark-ups do occur which lead to misleading structural measurements. Thus it is imperative that quality assurance/quality control (QAQC) practices are in place to identify this. When orientation mark-ups fail (often associated with zones of broken ground that cannot be reconstructed) this results in zones of unorientated core that can be several meters long. These zones generally occur through significant structures that would greatly benefit from orientated core. To combat this, televiewer surveys can be carried out to obtain this data.

While the data used for a structural geology model is important, the method of creating the model is also equally important in creating realistic models of the geology. Various 3D software programs are available for the presentation and interpretation of geological information. Standard mining packages enable drillhole traces and mapping information to be displayed. However, traditional modelling practices in these packages can be time consuming and can create unnecessary bias. To combat this, geological modelling specific software packages such as Leapfrog ${ }^{\circledR}$ (ARANZ Geo Ltd, 2013) and GOCAD ${ }^{\circledR}$ (Paradigm Ltd, 2013) have been developed. These packages use implicit modelling principles which significantly reduce the time required to create a model and enable numerous geometries to be tested quickly to determine which makes the most geological sense. However, care needs to be taken, as the model will only be as good as the person creating it.

In addition to these geological modelling software packages, software packages that model discrete fracture networks (DFN), such as FracMan ${ }^{\circledR}$ (Golder Associates, 2012) Petrel (Schlumberger Ltd, 2013), DFN Modeler (Pashin et al., 2008), which are typically used in the oil and gas industry can be equally useful for mining applications. These programs generate 3D fracture network models to provide a more realistic description of the pattern of faults, fractures, solution features and stratigraphic contacts in fractured rock. FracMan ${ }^{\circledast}$ for example, also provides a range of approaches for generation of fracture patterns to suit any kind of geology, including stochastic models, fault and fold geological models, geocellular models, and stress tensor models. However, due to the inherent complexity in the use of these programs it is essential that these are generated by experienced and trained users.

\section{Drillhole data}

Drillhole data commonly forms the starting point of any geological investigation, particularly in Western Australia where outcrop is rarely present. Drillhole information comes in a variety of forms including RC drilling which is a great starting point, but provides no structural information apart from the approximate location of lithological contacts. Diamond drilling provides core samples that can be used to determine the location, orientation (assuming orientated core), and physical properties of geological structures and defects and when used in conjunction with borehole imagery data which provides a geophysical 
representation of the hole, is particularly useful through zones of poor core rock quality which often result in un-orientated core.

In addition to the type of drilling data available, the location and orientation of the drillholes is also of equal concern. It is important to remember that drillholes only provide a very limited sample of the rock mass. While the orientation of a drillhole may be useful for the identification of certain structures and lithological contacts, it may totally miss or misrepresent others.

\subsection{Drillhole accuracy}

Various factors can come into play regarding the accuracy of drillhole data. While QAQC practices should be in place to pick up these issues, they should always be independently assessed when using the data for geological modelling. These issues can include but are not limited to: collar location, downhole survey, metre marks and orientation line.

While the exact location and orientation of the drillhole may vary slightly from the survey information, it will generally only have a minimal impact on the location of specific intersections, with the largest deviations occurring at the end of long holes (generally associated with surface holes drilled for underground operations). The inclusion of more spatially accurate data for geological modelling, including mapping data (traditional and photogrammetric) and more accurate drilling data (shorter drillholes drilled within pit or from underground locations) can highlight the possible deviation of longer drillholes. In such situations, it is advisable that the least spatially accurate data be disregarded to prevent unrealistic modelling. For auditing purposes, these intersections should for example be kept electronically in a separate layer so that it is recognisable that the intersection has been assessed.

By contrast, the inaccurate mark-up of orientation lines and metre marks can have a much greater impact upon the accurate modelling of geological structures. The task of marking up orientation lines and metre marks generally sits with the core-technicians, who may or may not fully understand the implications of poor mark-up. Some of the issues with marking up tend to arise when core is left in the tray, this tends to occur more often when core is not being orientated, and thus this can be easily rectified by following the correct procedures. In regards to orientation line mark-up, best practice is to align three or more orientation marks prior to drawing the orientation line. Where less than three can be aligned, caution should be taken and the logging should reflect this.

The main issue with the inability to align orientation marks is generally due to the method used by the drilling contractor to mark the core. Various methods for orientating core exist; these include the down hole spear, Ezy-Mark ${ }^{\circledR}$ (2iC Australia Pty Ltd, 2013a), Ballmark ${ }^{\circledR}$ (Ballmark Chile, 2013) and Reflex ${ }^{\circledR}$ (Imdex Limited, 2013) systems. All of these systems require the drillhole to be inclined. An orientation tool is also available which is capable of reliably orientating vertical boreholes; the Verti-Ori ${ }^{\mathrm{TM}}$ (2iC Australia Pty Ltd, 2013b) system is primarily a core orientation tool designed for producing 'magnetic north' core orientations from vertical holes. The authors have used this tool and validated the results with televiewer data collected. All methods, when used properly with good quality equipment and procedures can produce reliable orientation marks. It is when the equipment is not operating correctly and procedures are not followed that issues arise. Errors most commonly occur when the spear tool is used. The spear tool is the simplest method for orientating inclined holes. Errors can occur due to the spear being bent or distorted; this can be overcome by inspecting the spear prior to use. Errors also occur due to the spear being dropped too quickly which can result in bouncing, causing multiple marks to be recorded. Care should also be taken when using the spear tool for smaller diameter core such as NQ ( $47.6 \mathrm{~mm}$ core diameter) as the orientation mark generally occurs too close to the centre of the core for a reliable reading (Holcombe et al., 2012). Davis and Cowan (2012) also discuss issues with core orientation in detail.

Regardless of the method of core orientation, it is always important to be clear on whether the orientation line on the core has been marked on the top of the core or the bottom of the core. Most orientation tools will mark the bottom of the core. Errors in assuming one way or the other have significant implications to the true orientation of the measured structural features. 


\section{$2.2 \quad$ Structural measurements}

A vast quantity of structural information can be obtained from orientated drill core provided accurate orientation lines have been marked up. The data that is collected generally falls into three categories depending upon the purpose of the logging. Geological logging will either include no measurements (if the core hasn't been orientated) or a minimum number of measurements restricted to contacts and major structures. Structural geologists tend to collect more measurements including contacts, major/minor structures, veins, joint sets etc. (anything that will aid in the creation of a structural model); while geotechnical engineers tend to collect the greatest volume of measurements by measuring every open joint or defect present. Unfortunately, not all core is orientated, thus not all measurements can be measured with both alpha and beta readings, leading to a jumbled array of information which needs to be understood.

Poor core quality, commonly associated with significant structures, often leads to an inability to orientate the core, resulting in no measurements. Likewise the highly weathered nature of much of the Australian land mass, along with tropical land masses often results in core that cannot be orientated, leaving weathered near surface relict structures unmeasured. While this may have been a barrier in the past, advances in downhole geophysical survey techniques means that this information no longer needs to be lost. The relatively low cost of collecting televiewer data ( $10 \%$ of the cost of drilling the hole) is outweighed by the information that can be obtained from this data. This data should be collected at the very minimum with mechanical calliper information which not only then provides reliable orientation data for the entire hole (including upper weathered zones) but also information on the foliation, spacing, width and aperture of structures and also zones of borehole breakout. The breakout zones can be very useful in the identification and validation of the in situ stress regime at depth.

Two different methods or technologies are available for televiewer data collection: the first uses the acoustic signal from a rotating sonar transducer and is called an 'acoustic televiewer'. The second uses a high resolution digital colour camera with a light source and is an 'optical televiewer'. The optical televiewer offers an advantage and attraction for geologists since it images the natural rock colours. It is like being able to see the actual core, which has the benefit of being able to identify rock types and possibly determine fracture infill types. The optical televiewer however requires clear fluid, or an empty, clean borehole (hence the use of drill muds and grease by the majority of Australian drilling contractors often affects the accuracy of this tool). On the other hand, the acoustic televiewer only requires borehole fluid. The acoustic televiewer is more reliable for a wider variety of applications, because it is often easier to use mud to keep fluid in the hole than to either flush the hole clean, or empty it, or wait until the fluid clears up.

Regardless of the method used, the structural information obtained from the borehole imagery removes a lot of the errors associated with manual core mark-up processes including providing accurate depth measurements and orientation measurement accuracy to a higher level of detail, provided post processing is conducted correctly. Conventional alpha and beta measurements are often limited to a minimum 5 degree error in orientation (based on experience); depending on the thickness of the orientation line itself and the tool being used to measure these angles. The measurement errors are significantly reduced by televiewer picking. Televiewer orientation measurements are also not affected by a rotating orientation line.

When televiewer information is processed using automated picking techniques, or by inexperienced geophysical analysts then you can often end up with hundreds or thousands of structural picks in a relatively short hole. These picks may not be representative of the significant structural features in the core and results in a lot of filtering through the data to find the useful information. For this reason it is recommended that the structural picking and analysis is carried out with comparison to the core photographs, or in the absence of core, with an optical survey of the hole to obtain information on the key structural features. 
If you were to take the potentially hundreds of measurements of structural features from the televiewer without any validation, then you may incorrectly identify structural sets or features that are irrelevant in terms of stability, and may mask the key features. If you are using external contractors to process the data then it is important that you provide them with core photographs and core logs to identify structures, but also that you establish with them how they identify structural feature types and what their specific structural legends are i.e. closed feature versus open feature or fault versus shear.

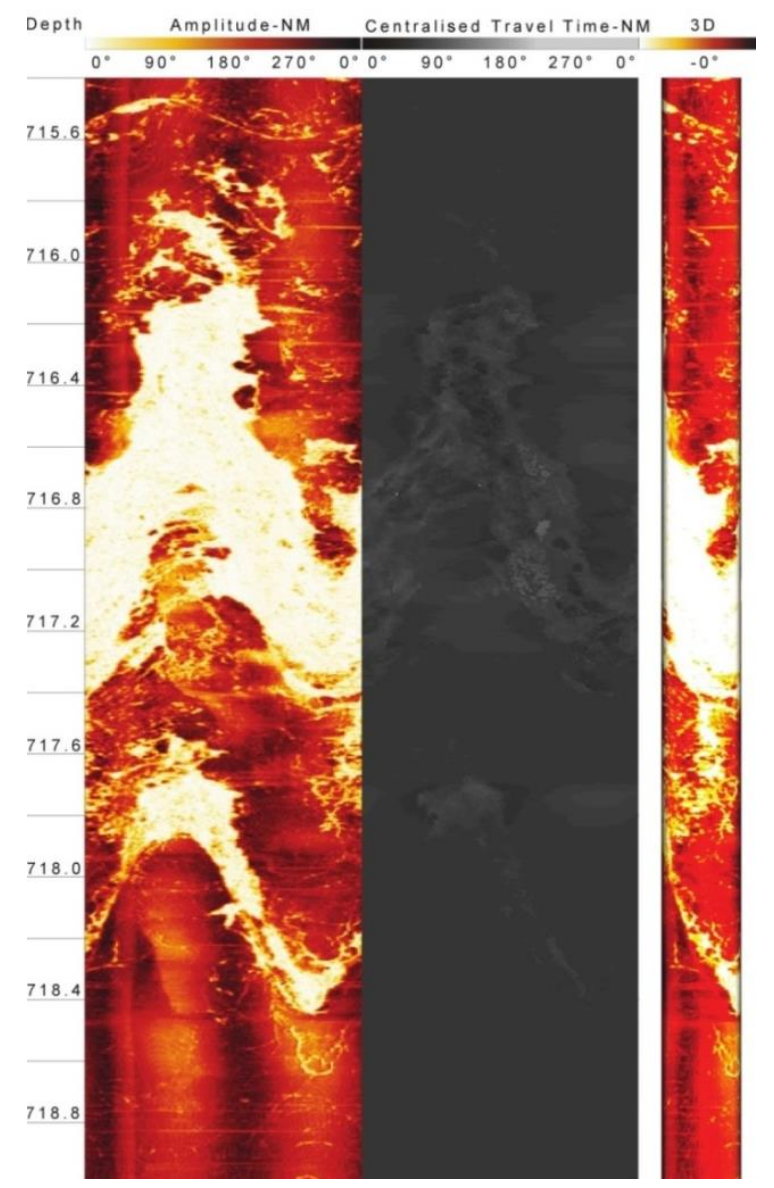

(a)

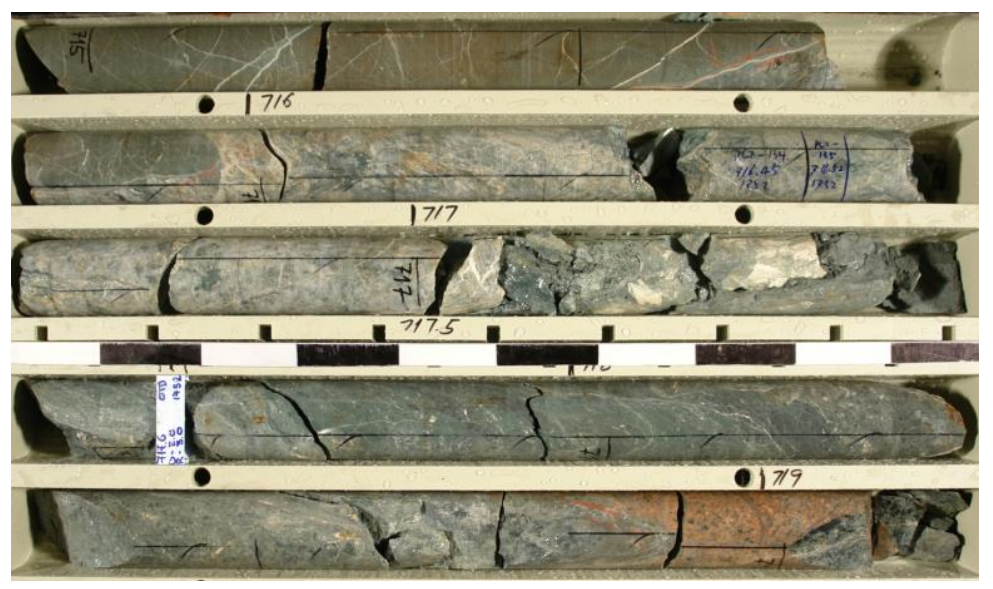

(b)

Figure 1 (a) Acoustic televiewer image of a diamond drillhole; (b) core photograph of the same section of drillhole showing shear structure from 717 to $717.5 \mathrm{~m}$ 
The televiewer structural database should be combined and analysed in conjunction with manual logging to get the full set of information on the defects. Figure 1 shows an acoustic televiewer log of a drillhole and associated core photograph for the same section of the drillhole. Using these data you are able to identify the shear at 717 to $717.5 \mathrm{~m}$ deep. Of importance to note, is that with longer drillholes in particular, you can get some stretching of the wire line cable. This does ultimately result in some distortion to the actual depth measured by the televiewer, which can be in the order of 0.1 to $0.5 \%$ of the depth of the hole in more extreme cases. It is therefore important to realise that the core logs and photos and televiewer data may not necessarily match up with each other. It is also an important consideration if you are planning on running the televiewer down hundreds of RC holes with no calibration to any cored hole. Calibration of the wireline is commonly done in the oil and gas industry, where the holes are typically much deeper, however it is not often seen in the mining industry.

\section{Geological mapping}

The mapping of geological structures is an integral part for understanding the rock mass of a particular area. Various methods can be employed in the creation of a geological map. However, it is important to remember that maps are simply geologist's interpretation of what they see and depending upon their area of expertise, very different maps can be created for the one area. While the basic elements of the various maps should correlate, specialist information such as fracture frequency, important for geotechnical evaluation, is an item often not recorded unless the mapping has been carried out by a geotechnical engineer. As such, how can you ensure that all of the required information is obtained?

Adequate training of personnel is paramount in any operation. Consistency in mapping style can aid greatly in the geological understanding of an area. By ensuring that all personnel are adequately trained, numerous problems can be overcome. However, experience is something that you can't teach and generally it is the least experienced personnel that carry out the important task of collecting this information. Even when the most experienced person does the mapping, the ability to translate $3 \mathrm{D}$ information onto a 2D map accurately has its issues. Knowing the exact location of structures goes a long way to being able to mitigate risk in mining. Conventional wall mapping can achieve this by marking up structures with paint for survey to pick-up, however the need to sometimes be able to take a step back to see the bigger picture cannot always be achieved, particularly where space is at a premium.

The alternative to traditional mapping is photogrammetry. Photogrammetry involves the collection of stereopair photographs which are used to create a 3D image of the area in question. Survey control points can be marked up in the photograph, enabling the geographical registration of the 3D image. This enables mapping to be carried out in a digital environment. The location of structures and areas of interest can be directly included into the geological model (Figure 2). Furthermore, the collection of high resolution spatially located 3D images means that the information is not lost following further mining, slope instability or the addition of surface support such as fibrecrete. By collecting these 'permanent' digital images as mining progresses, you are also collecting valuable information which is critical in back-analysing and understanding any instabilities or failures that may have since occurred. While you still may task your junior geologists with the mapping, QAQC can quickly and easily be carried out by more senior and experienced staff. It should however be noted that not all required information can be collected from photogrammetry images, particularly for geotechnical purposed. Small scale information such as joint infill and joint roughness cannot be seen in these images; however this can be mitigated by correlating joint set data from mapping with drillhole data, or by carrying out field observations in areas that can be accessed. Despite some cons, photogrammetry provides many advantages, including being able to access areas not readily available and being able to assess the broader structural geology geometry whilst also including alternative datasets in the analysis. As with all data sets, analysis should not be carried out in isolation, but instead by integrating the multiple dataset available.

The integration of multiple datasets in structural geology modelling is extremely beneficial. One advantage of using digital 3D images for mapping is that they can be assessed alongside pre-existing interpretations, drillhole traces, seismic data etc. Intersections of major structures can be digitised directly into the working 
model, enabling the use of up to date information for mining purposes. The benefits of using photogrammetry data for geological interpretation are discussed in detail by Rees (2012).

An area often ignored following initial exploration activities is the use of surface geophysical and aerial imagery. Airborne magnetics and aerial photography provides a wealth of information for structural geology interpretation. High quality aerial photography is available over much of Australia and large regions in the rest of the world and geophysical surveys can be readily obtained or carried out. These data types can provide a broad scale view of the regional geological geometry, providing a starting point for further structural interpretation.

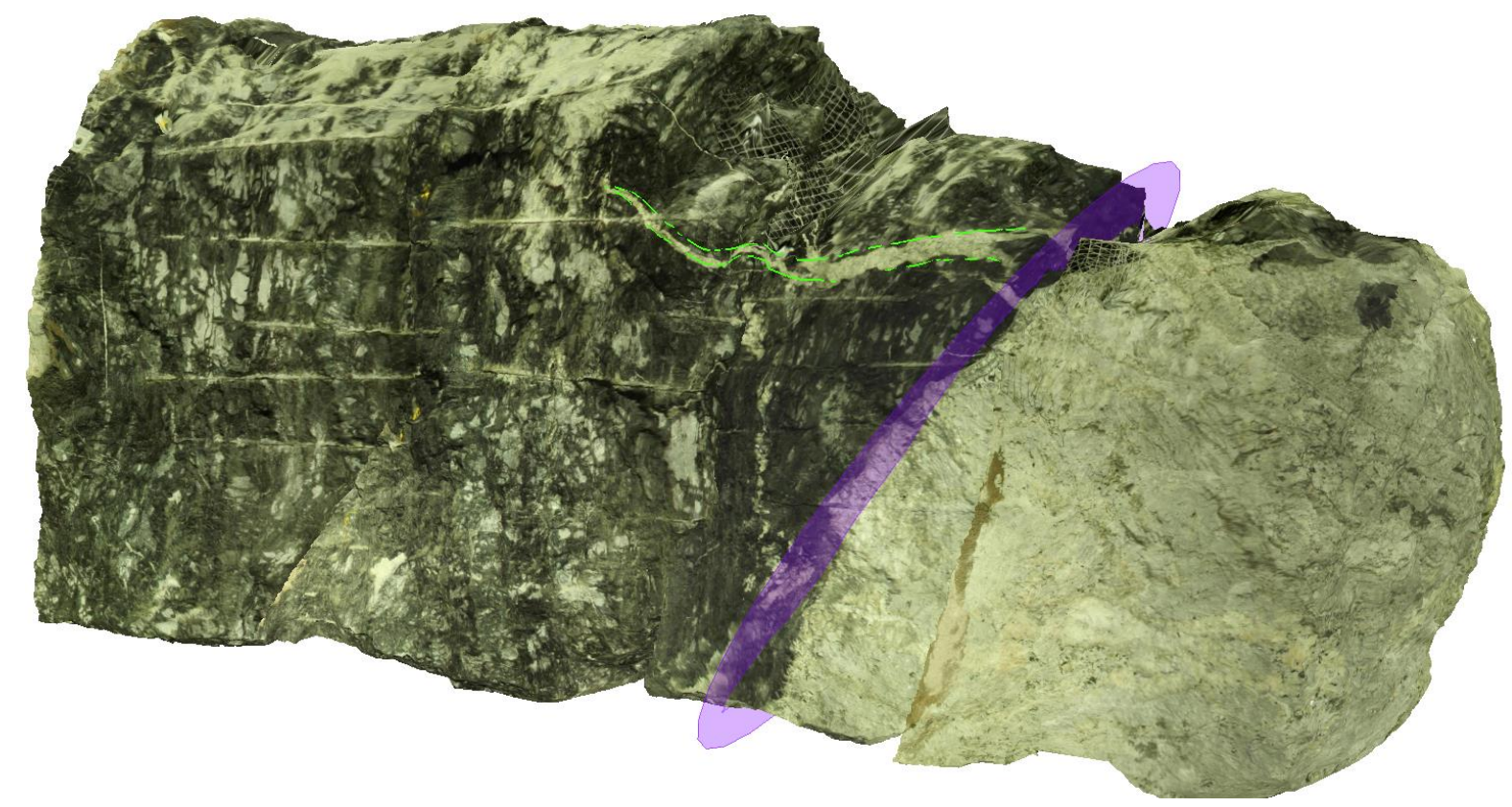

Figure 2 Example of a photogrammetry image from an underground drive, showing digitised plane along lithological contact

\section{$4 \quad$ Three-dimensional modelling packages}

The method for undertaking geological interpretation has come a long way from sectional interpretations on paper. 3D geological models are common place these days, but the main method used for creating these models hardly differs from the paper interpretations of yesteryear. The use of traditional mining software packages for geological modelling requires the input of either string or point data to create the model. This is generally carried out by creating sectional polygonal interpretations which is hardly making the most of the 3D environment. Modelling in this fashion is time consuming and can lead to the production of unrealistic models. It is not uncommon for models produced in this way to look very jagged when cut in long section perpendicular to the sectional interpretation orientation. Various methods can be employed to overcome this, one being the remodelling of the sections, with another simply being the use of the point data to create the surface, however this method still requires the selection of all of the point data which is very time consuming. Fortunately, others have also discovered these issues, leading to the creation of geology modelling specific software packages such as Leapfrog $^{\circledR}$ and $\mathrm{GOCAD}^{\circledR}$.

Implicit modelling forms the basis of both the Leapfrog ${ }^{\circledR}$ and $\mathrm{GOCAD}^{\circledR}$ systems. Implicit modelling involves the automatic modelling of selected data values such as rock type, eliminating the need to pick all of the points individually (Chalke et al., 2012). While the initial model created can often suffice, additional interpretational strings can be added to get the model to do exactly what you need it to. This fast and efficient modelling system can enable multiple scenarios to be tested quickly and easily. Though many geologists may be weary of the ease at which a model can be created, seemingly by anyone, the model will only ever be as good as the data used and the person creating it. The need to validate the model does not disappear with this system, it is simply made easier to undertake. 
DFN Modelling software allows the user to model the rock mass fracture system by explicitly building a 3D network of both deterministically mapped structure but also stochastically generated structures for the generation of geologically realistic fracture networks based on structural, geomechanics and geological principles. It allows multiple data sources to be incorporated into the modelling including televiewer logs, oriented core, bench and face mapping, photogrammetric surveys to derive the orientation properties of the network. Some of these programs (i.e. $\operatorname{FracMan}^{\circledR}$ ) also have the capability of providing information on fracture size and intensity through implicit empirical and stochastic relationships. The interpretation of the fracture intensity logs from boreholes can then be used to derive 3D fracture intensity patterns.

Fracture patterns can include planar and non-planar faults and can be conditioned to field observations. The ability to create a discrete fracture network based upon drillhole information, can lead to the identification of zones of weakness associated with close fracture spacing, but also understand the directional bias in the orientation of these fractures related to the orientation of the drilling, a feature that is often ignored, but is critical to understand if trying to generate a 'block model' of geotechnical parameters. Zones of differing fracture intensity are easily identified; high fracture intensity is important and can be representative of shear zones and ultimately affect the integrity of the rock mass.

All level of structural modelling can be carried out in any of these systems, including major/minor faults, shear zones, joints and intermediate scale structures. The modelling potential is simply limited by the level of information collected through the drillhole logging and geological mapping stages, in addition to the level of experience of the person creating the model.

\section{Discussion}

We are biased by the things that we have experienced. Hence a stratigrapher will look at a rock and be able to tell you about the sedimentary history, but will often miss structural information as their eyes have not been trained to pick it up. In the same way a resource geologist focuses on grade and ore rather than structures, while a geotechnical engineer is more interested in fracture frequency, orientation, infill and the location of major structures, but not necessarily in the genesis, offset and relative timing of these features. The essential thing to remember in this is that the data that we use for structural geology modelling is subjective. Drill programs only 'sample' the rock mass, they by no means tell us everything that is going on. Even if they did, it is highly unlikely that every facet of information would be collected. Therefore it is important to remember that structural geology models are only as good as the data used to create them. Every model is subject to change as new information comes to hand. With this in mind, the importance of collecting high quality data is clear. The biggest road block to collecting this level of information is people. So how do we encourage those collecting the information to up their game?

A key aspect when constructing a model is to question the validity of the data. It is important to appreciate the reliability of the information that you are using but also so you can understand the uncertainty in your model.

Some questions you might want to consider include:

- Who collected the data? (i.e. geologist, engineer, graduate or experienced)

- How old is the data?

- Is the data in 3D format? Is the data available electronically? Was it collected electronically?

- Am I using acoustic or optical televiewer data?

- Are core photographs available for QAQC? Were core photographs used to validate geological, structural and televiewer interpretations?

- Is there an auditable trace for the mapping data? Do I know if information was discarded or ignored in the data collection process?

- Can I talk to the person or people that collected the data? 
In the current financial climate, there is a focus on reducing costs. This can seem like a hurdle when trying to get procedures in place to increase data accuracy, particularly when these new and improved systems cost time and money. The key is to inform the decision makers about the long term benefits of implementing these new systems and highlighting the value and efficiency that can be added by implementing these systems.

\section{Conclusions}

The accuracy of any geological model depends upon the quality of the data used. Advances in technology such as photogrammetry and televiewer surveys should be utilised to ensure data integrity. These new and improved techniques increase data collection and processing efficiency, enabling more time to be spent on the ever increasing list of tasks one needs to carry out. A well-defined structural geology model which takes advantage of quality data and is produced using non-biased modelling methods is the key to reducing these risks. The collection of poor quality data appears to be an accepted practice at many mines throughout Australia. Either that or personnel simply don't have the time or inclination to implement change. It is important to up skill and empower those collecting the data to ensure that we are getting the most out of every situation.

\section{References}

2iC Australia Pty Ltd (2013a) Ezy-Mark, http://www.2icaustralia.com.au/core-orientation/ezy-mark-features/.

2iC Australia Pty Ltd (2013b) Verti-Ori, http://www.2icaustralia.com.au/products/verti-ori/.

ARANZ Geo Ltd (2013) Leapfrog, http://www.leapfrog3d.com/.

Ballmark Chile (2013) Ballmark, http://ballmarkchile.com/index_2.html.

Chalke, T., McGaughey, J. and Perron, G. (2012) 3D software technology for structural interpretation and modelling, in Proceedings Structural Geology and Resources 2012 Conference, J. Vearncombe (ed), 26-27 September 2012, Kalgoorlie, Australia, Australian Institute of Geoscientists, Brisbane, pp. 16-20.

Davis, B.K. and Cowan, E.J. (2012) Orientated Core - What the...?, in Proceedings Structural Geology and Resources 2012 Conference, J. Vearncombe (ed), 26-27 September 2012, Kalgoorlie, Australia, Australian Institute of Geoscientists, Brisbane, pp. 61-63.

Golder Associates (2013) FracMan version 7.4, http://www.fracman.com/home/software/fracman-version-history/softwarefracman-7-4/.

Holcombe, R., Caughlin, T. and Oliver, N. (2012) Orientated Drillcore: Measurement and calculation procedures for structural and exploration geologists, HolcombeCoughlinOliver, viewed 15 July 2013, http://www.holcombecoughlinoliver.com/ downloads/HCO_oriented_core_procedures.pdf.

Imdex Limited (2013) Reflex, http://www.reflexinstruments.com/en/.

Paradigm Ltd (2013) GOCAD, http://www.pdgm.com/products/GOCAD.

Pashin, J.C., Jin, G., Zheng, C., Chen, S. and Mclntyre, M.R. (2008) Discrete Fracture Network Models for Risk Assessment of Carbon Sequestration in Coal, Final Technical Report, Geological Survey of Alabama, viewed 9 August 2013, http://www.osti.gov/ bridge/servlets/purl/941131-PKaMA3/941131.pdf.

Rees, K. (2012) The benefits of using photogrammetry in the geological interpretation of the Cosmos nickel mine, in Proceedings Narrow Vein Mining 2012 Conference, S. Dominy (ed), 26-27 March 2012, Perth, Australia, The Australasian Institute of Mining and Metallurgy, Carlton, $145 \mathrm{p}$.

Schlumberger Ltd. (2013) Petrel, http://www.software.slb.com/products/platform/Pages/petrel.aspx. 
